\title{
ANÁLISE COMPARATIVA DE ACESSIBILIDADE DO CENTRO DE EVENTOS DO CEARÁ: DO PROJETO AO "AS BUILT".
}

\section{ACCESSIBILITY COMPARATIVE ANALYSIS OF EVENTS CENTER OF CEARÁ: OF THE PROJECT TO THE AS BUILT.}

\author{
Zilsa Santiado ${ }^{1}$, D.Sc \\ Raquel Pessoa Morano ${ }^{1}$, Mestranda \\ (1) Universidade Federal do Ceará (UFC) \\ e-mail: zilsa@arquitetura.ufc.br \\ (2) Universidade Federal do Ceará \\ e-mail: raquelmorano20@gmail.com
}

Palavras-chave: Acessibilidade, Centro de Eventos, As Built.

\begin{abstract}
As normas técnicas destinadas ao espaço construído existem para garantir sua padronização quanto a atributos como: qualidade, segurança, confiabilidade e eficiência. $\mathrm{O}$ objetivo desse trabalho é verificar se a acessibilidade prevista nas normas se aplica corretamente no equipamento Cultural Centro de Eventos do Ceará, através da metodologia de Avaliação Pós Ocupação (APO).
\end{abstract}

Key-words: Accessibility, Events Center, As Built.

The technical standards for the built space exist to guarantee its standardization in terms of attributes such as: quality, safety, reliability and efficiency. The objective of this work is to verify if the accessibility provided in the norms is correctly applied in the Cultural Center of Events of Ceará, through the methodology of Post-Occupancy Assessment (APO).

\section{Introdução}

Segundo a Organização das Nações Unidas (ONU), existem 191 países que reconhecem direitos das pessoas com deficiência e, somente 50 desses países possuem uma legislação ampla e avançada que contempla essas pessoas, o Brasil é um deles. A principal tarefa das normas de acessibilidade feitas pela Associação Brasileira de Normas Técnicas é a de romper obstáculos e ir além de dar diretrizes projetuais, formando uma cultura de inclusão e posturas perante o deficiente. Neste sentido, o decreto Federal n ${ }^{\circ}$. 5.296/2004 vai na mesma direção, do respeito ao cidadão, da prioridade e ao mesmo tempo considerando que a acessibilidade deve fazer parte dos atributos que compõem o espaço urbano e edificado, esclarecendo sobre conceitos, como desenho universal, paradigma que aponta para uma abordagem holística e integrada do design, envolvendo desde o planejamento do espaço da cidade até os detalhes na concepção de produtos.

Aproximando-se do tema a ser abordado no artigo, apontamos para a contribuição principal que um profissional da Arquitetura pode oferecer na produção espacial. Segundo o Decreto 5.296/2004 para regulamentar a Lei 10.048/2000, traz a
Realização:
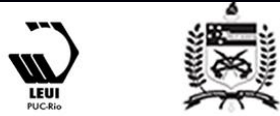


\section{$16^{\circ}$ \\ ERGODESIGN USIHC CINAHPA}

definição de acessibilidade como:

\begin{abstract}
“Condição para utilização, com segurança e autonomia, total ou assistida, dos espaços, mobiliários e equipamentos urbanos, das edificações, dos serviços de transporte e dos dispositivos, sistemas e meios de comunicação e informação, por pessoa portadora de deficiência ou com mobilidade reduzida. " (BRASIL. Decreto $\mathrm{N}^{\mathrm{o}} 5.296,2004$ ).
\end{abstract}

Dessa maneira, ao projetar espaços torna-se indispensável trabalhar o conceito acessibilidade de uma forma ampla e universal, entendendo que o usuário é um ser humano tão variado quanto a espécie permite. Pessoas com algum tipo de deficiência já representam hoje $24 \%$ da população no país, ou seja, um em cada quatro brasileiros (Censo 2010, IBGE).

A padronização de elementos arquitetônicos continua a contribuir para a formação de barreiras. A relevância da acessibilidade espacial é reforçada por lei em espaços públicos e coletivos. No caso de equipamentos de lazer, artístico e cultural, o não cumprimento desses direitos pode restringir seu potencial inclusivo, já que as barreiras físicas e sociais ocasionam a não participação de todos os seus possíveis usuários, tais como as pessoas que possuem algum tipo de restrição, seja alguma deficiência, ou mobilidade reduzida. No entanto, o direito ao lazer e à cultura é um direito social, determinante e condicionante da saúde; é um direito à cidadania que está previsto em muitas normas jurídicas.

Reconhecendo a importância do desenho universal em edifícios dessa tipologia, selecionamos para nosso objeto de estudo, o Centro de Eventos do Ceará - CEC (Figura 01), pela sua relevância para o Estado. Além do fluxo intenso de pessoas que passam por ali todos os dias, o Centro de Eventos recebe um grande volume de atividades que atendem diferentes grupos de pessoas com idades variadas e por isso mesmo, se faz obrigatório e essencial ser acessível para atender a demanda de uso.

$\mathrm{O}$ artigo traz como objetivo avaliar o processo de projeto do CEC em suas fases versus a situação $16^{\circ}$ Ergodesign - Congresso Internacional de Ergonomia e Usabilidade de Interfaces Humano Tecnológica: Produto, Informações Ambientes Construídos e Transporte

$16^{\circ}$ USIHC - Congresso Internacional de Ergonomia e Usabilidade de Interfaces Humano Computador

CINAHPA | 2017 - Congresso Internacional de Ambientes Hipermídia para Aprendizagem.

construída e de uso - "as built"- no quesito de acessibilidade. Para isso, o método de Avaliação Pós-Ocupação foi aplicado a fim de identificar possíveis divergências entre projeto e execução, falhas técnicas e aspectos positivos relacionados à acessibilidade do edifício, bem como verificar suas características de desempenho e a qualidade de uso. Devido à ampla área construída do CEC, para apresentação neste artigo, foi necessário um recorte espacial. Nos aprofundamos na avaliação dos banheiros e sanitários principais no que diz respeito a usabilidade, pois são áreas que exigem maiores cuidados no que diz respeito à acessibilidade.

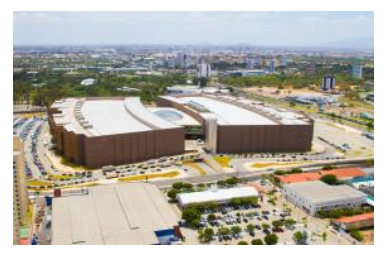

Figura 1: Centro de Eventos do Ceará - Vista Aérea. Fonte:

http://rotadosolce.blogspot.com.br/2015_09_20_archive .html Acesso em: 07/02/2017.

\section{Caracterização do objeto do estudo}

A concepção do CEC se deu por vários motivos, dentre eles, a condição física do antigo Centro de Convenções, situado na mesma avenida e bairro, cujas dimensões já não comportavam grandes eventos, além da necessidade de incluir o Ceará na rota dos eventos de negócios, de forma a se ter condições de estimular o chamado turismo de negócios, estratégia do governo para compensar os períodos de baixa estação no setor. (GOIS, 2013).

O edifício está localizado na Avenida Washington Soares, no Bairro Edson Queiroz, na parte sudeste de Fortaleza, eixo de desenvolvimento de novas centralidades (Figura 2), à 7 km da Av. Beira-Mar.

O CEC possui dois pavilhões de $13.780 \mathrm{~m}^{2}$, ambos com capacidade para 30 mil pessoas. $\mathrm{O}$ espaço dos pavilhões é flexível, de modo a permitir a ocorrência de vários eventos simultaneamente com entradas específicas para cada espaço, é possível ter eventos de fluxo, vocação e densidade volumétrica distintas, sem que um interfira no
Realização:

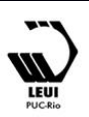




\section{$16^{\circ}$ \\ ERGODESIGN USIHC CINAHPA}

outro (Figura 3).

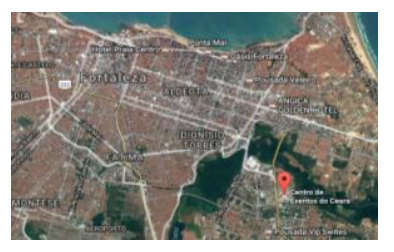

Figura 2: Mapa parcial de Fortaleza - Centro de Eventos. Fonte: https://www.google.com.br/maps

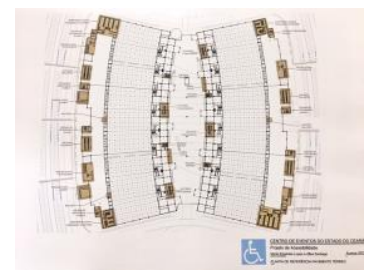

Figura 3: Planta Baixa Centro de Eventos. Fonte: Projeto de Acessibilidade

\section{Metodologia da Pesquisa}

O conhecimento sistematizado hoje existente sobre as questões de acessibilidade no espaço edificado, desde os autores consagrados [Dreyfuss, 1955; Goldsmith, 1976; Panero e Zelnik, 1989; Preiser, 2001] e trabalhos mais recentes [Cambiaghi, 2004; Lopes, 2005; Santiago, 2005; Ornstein et al, 2010; Cohen et al, 2012; Dischinger et al, 2012] fundamentam pesquisas na área e, cada novo objeto de estudo busca contribuir para o debate de como este assunto está inserido na produção arquitetônica, frente à necessidade de atender da melhor maneira a diversidade humana. Neste sentido, acontecem as revisões das normas brasileiras e novas leis surgem para amparar as pessoas em seus direitos e os projetos em seus propósitos de assegurar a acessibilidade para um maior número de pessoas com deficiência ou mobilidade reduzida.

Nesta pesquisa, nos apoiamos nos estudos de Avaliação Pós-Ocupação - APO [Ornstein, 1992; Santiago, 2005] como referências à metodologia pesquisa de campo, bem como outras referências [Cohen et al, 2012; Dischinger et al, 2012], além de normas e legislação [NBR 9050/2004 e Decreto 5.296/2004]. As autoras consideraram a análise não deveria tomar como base a NBR 9050/2015 devido $16^{\circ}$ Ergodesign - Congresso Internacional de Ergonomia e Usabilidade de Interfaces Humano Tecnológica: Produto, Informações Ambientes Construídos e Transporte

$16^{\circ}$ USIHC - Congresso Internacional de Ergonomia e Usabilidade de Interfaces Humano Computador

CINAHPA | 2017 - Congresso Internacional de Ambientes Hipermídia para Aprendizagem.

a edificação/objeto de estudo ter sido construída antes da homologação desta norma, tendo seu projeto executado sob a vigência da NBR 9050/2004, embora admitem que em outro momento, possam ser feitas considerações a cerca de possíveis adequações.

Os quesitos aqui apresentados são referentes aos elementos de acessibilidade no acesso e uso dos sanitários e banheiros a serem analisados: Sinalização e condição de acesso; Portas (maçaneta, proteção, barra); Bancada de lavatório (altura de bancada, altura livre, área de aproximação; barra de apoio); Altura dos elementos/acessórios (inclui espelho); Tipo de torneira; Sanitário (posição, altura, área de aproximação); Descarga (tipo, altura); Barras de apoio em sanitário (altura, localização, dimensão); Existência de sanitários infantis; lay out dos boxes acessíveis no sanitário coletivo; Existência de barras/puxadores nos boxes acessíveis; sanitáriofamília (fraldário); Mictório (espaçamento, barra de apoio); Iluminação dos sanitários (sensor); Botão de emergência para sanitário individual; Vestiário/sanitário funcionários.

\section{Resultados}

De um modo geral, o projeto demonstra, desde o início de sua concepção, o compromisso com a acessibilidade espacial, visto que, os autores do projeto, Escritório Nasser Hissa Arquitetos Associados, buscaram consultoria iniciada pelo Termo de Referência - Acessibilidade Física (Santiago e Lopes, 2008), além de Diagnóstico de Acessibilidade, de mesma autoria, contendo as indicações dos pontos que deveriam ser objeto de revisão no projeto, mostrando a importância e destacando ser indispensável a aplicação da legislação e das normas pertinentes ao tema.

No processo de desenvolvimento do projeto executivo, modificações foram realizadas, inclusive nos banheiros e sanitários. As primeiras modificações observadas foram na localização dos sanitários com acesso independente e no banheiro família. Mesmo com as modificações, que podem ter ocorrido em função de outros elementos do projeto, podemos analisar cada modelo 


\section{$16^{\circ}$ \\ ERGODESIGN USIHC CINAHPA}

diferenciado. Apresentamos a estrutura geral e localização de cada sanitário para que se possa entender como estão distribuídos no edifício e os vários formatos que integram cada conjunto. Sigamos na análise de cada tipo.

\subsection{Sanitários Públicos 1 e 2 - Térreo}

Os conjuntos de sanitários denominados WC Público 1 e 2 estão localizados nos extremos opostos do pavimento térreo, conforme representados nas figuras 4 e 5 .
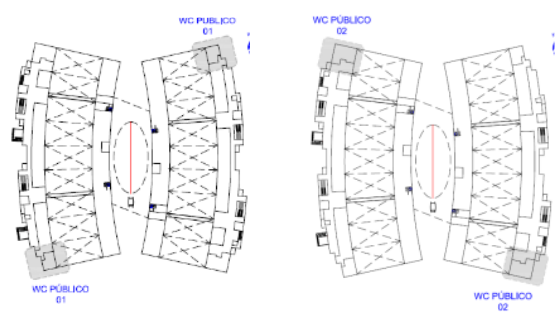

Figura 4 (à esq.): WC Público 01. Fonte: Architectus, 2010. Figura 5 (à dir): WC Público 02. Fonte: Architectus, 2010.

No projeto básico era denominado Modelo A e B, já no projeto executivo, foi denominado WC público-1 e WC público-2. O modelo WC Público1 (Figura 6) contém boxes de três tipos: boxes do padrão comum, boxes acessíveis internos, tanto no masculino como no feminino, além dos boxes acessíveis externos.

As condições gerais de acesso, sinalização e gabarito de acessórios estão em conformidade com as definições da NBR 9050/2004.
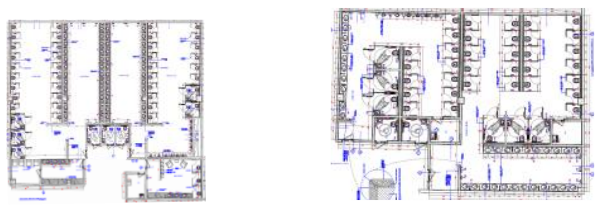

Figura 6 (esq): WC Público 01. Fonte: Architectus, 2010. Figura 7(dir): WC Público 02. Fonte: Architectus, 2010.

No coletivo do WC Público-1, a parte da bancada, apresenta duas alturas e a torneira é do tipo pressão, ambos atendem aos requisitos da norma. Já o espelho, encontra-se na altura de 1,30m, esta $16^{\circ}$ Ergodesign - Congresso Internacional de Ergonomia e Usabilidade de Interfaces Humano Tecnológica: Produto, Informações Ambientes Construídos e Transporte

$16^{\circ}$ USIHC - Congresso Internacional de Ergonomia e Usabilidade de Interfaces Humano Computador

CINAHPA | 2017 - Congresso Internacional de Ambientes Hipermídia para Aprendizagem.

altura não contempla pessoas de baixa estatura, embora tenha os boxes acessíveis internos e externos.

O modelo A ou WC Público-2 (Fig. 7), repete, praticamente, as condições do WC Público-1, com boxes de três tipos: boxes do padrão comum, boxes acessíveis internos, tanto no masculino como no feminino, além dos boxes acessíveis externos. Apresenta ainda sanitário do tipo: "Família" e "Amamentação". Sendo que na visita para o "as built", este último se encontrava fechado, não sendo possível constatar a compatibilização com o projeto executivo.

As condições de acesso, sinalização, gabarito de acessórios, todos estes itens estão em conformidade com as definições da NBR.

Aqui, as condições das bancadas do coletivo se repetem, apresentam duas alturas e a torneira é do tipo pressão, ambos atendem aos requisitos da norma. $\mathrm{O}$ espelho, no entanto, encontra-se na altura mínima de $1,30 \mathrm{~m}$, esta altura não contempla pessoas de baixa estatura, embora tenha os boxes acessíveis internos e externos.

O Box acessível interno apresenta positivamente o acesso, altura do sanitário e descarga, altura de acessórios e lavatório. Contudo, as barras de apoio ao sanitário além de apresentarem altura de $87 \mathrm{~cm}$, acima da recomendação registrada no projeto executivo, de $75 \mathrm{~cm}$, o espelho junto ao lavatório, encontra-se a $96 \mathrm{~cm}$ do piso, já no projeto executivo está de $90 \mathrm{~cm}$, portanto, sem apresentar inclinação, e a barra em torno do lavatório excede em $20 \mathrm{~cm}$ a profundidade do lavatório (Fig. 10), o que torna $\mathrm{o}$ acesso à torneira de $54 \mathrm{~cm}$, o que não acontecia no projeto executivo (Fig. 9), talvez tenha sido a dificuldade de encontrar dimensões compatíveis no mercado.
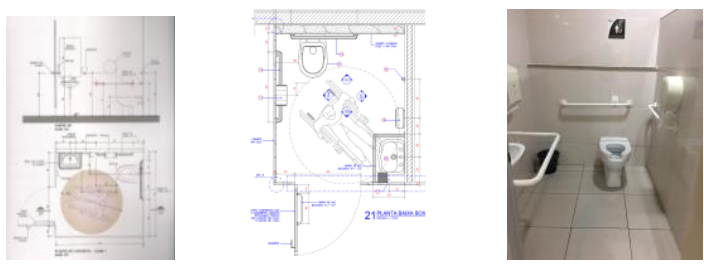

Figura 8 (à esq):
Realização:
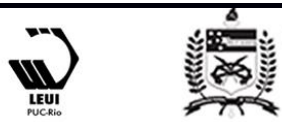


\section{$16^{\circ}$ \\ ERGODESIGN USIHC CINAHPA}

Diagnóstico. Fonte: D.A. 2008; Fig. 9 (meio): Proj Exec Fonte: Architectus, 2010; Fig. 10 (à dir): Box Acess. Interno Fonte: autoras, 2017.

No detalhamento do projeto, as dimensões e localização das barras de apoio estão corretas (Fig. 11), mas com o "as built" constatamos as barras laterais só ultrapassam $26 \mathrm{~cm}$ do sanitário, além disso a barra de apoio contornando o lavatório, tem dimensões excessivas deixam a área de aproximação prejudicada (Fig. 12).
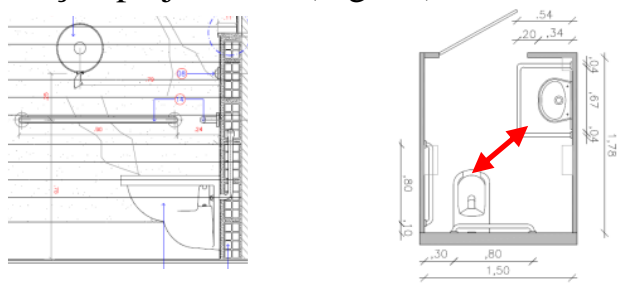

Fig.11: Projeto Executivo. Fonte: Architectus, 2010; Fig.12: "as built". Fonte: autoras, 2017.

Outro fato a ser posto como atualização de padrões é o assento com abertura na frente, de uso discutível na época, mas que a NBR 9050/2015 traz o argumento de que é impróprio para uso público, devendo ser utilizado restritamente em locais de tratamento de saúde como hospitais.

Outro aspecto observado é das portas dos boxes acessíveis não apresentam as barras horizontais internamente (Figura 13, 14), que foram especificadas no projeto executivo, conforme se observa nas Figuras 9, 13, 14.
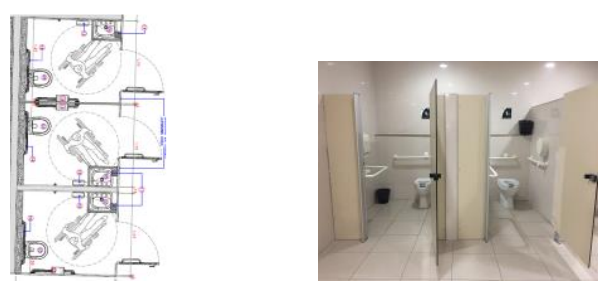

Figura 13 (à esq): WC publico 01, Fonte: Architectus, 2010. Figura 14 (à dir): WC Acessível interno 02,

Fonte: autoras, 2017.

No sanitário masculino coletivo, o Projeto

Executivo apresenta mictórios com dimensões, altura e barras de apoio conforme recomendações da NBR 9050 (Figura 15), mas na pesquisa in loco, contudo, verificamos que não foram colocadas as barras verticais de apoio (Figura 16).
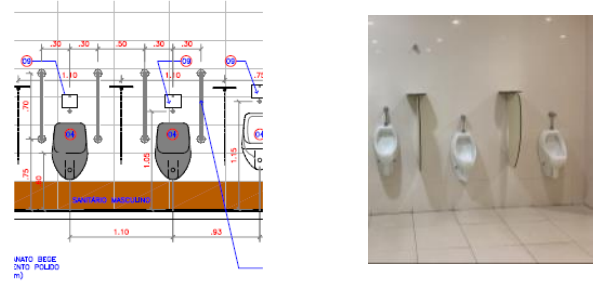

Fig.15 (à esq.):Projeto executivo, Fonte: Architectus, 2010; Fig. 16 (à dir): Coletivo-2 masculino, Fonte: Autoras, 2017.

\section{Considerações Finais}

Por meio da APO realizada no Centro de Eventos do Ceará, verificou-se que o espaço analisado não proporciona acessibilidade física plena a que se propõe. Em vários itens analisados, se constata a possibilidade de uso aos sanitários (recorte) por pessoas em cadeira de rodas ou pessoas com deficiência visual ser feita com a ajuda de acompanhantes, dessa maneira, a autonomia do usuário não está completamente garantida.

Apesar de apresentar falhas em relação à acessibilidade, não são necessárias grandes modificações para colocá-lo em conformidade com as normas de acessibilidade. Neste sentido, verificamos que o trabalho incessante de pesquisa e análise de condições de acessibilidade na sistemática da Avaliação Pós-Ocupação pode contribuir na ampliação dos debates e compreensão da temática, fortalecendo assim, a efetividade das políticas públicas tanto na direção da garantia dos direitos das pessoas com deficiência e mobilidade reduzida como na implementação de obras públicas e de uso coletivo que apresentem a condição de acessibilidade a todos, promovendo a cidadania.

\section{BIBLIOGRAFIA}

ASSOCIAÇÃO BRASILEIRA DE NORMAS TÉCNICAS. NBR 9050: Acessibilidade de Pessoas Portadoras de Deficiências a Edificações, Espaço, Mobiliário e Equipamento Urbano. Rio de Janeiro: ABNT, 2004. 


\section{$16^{\circ}$ \\ ERGODESIGN USIHC CINAHPA}

$16^{\circ}$ Ergodesign - Congresso Internacional de Ergonomia e Usabilidade de Interfaces Humano Tecnológica: Produto, Informações Ambientes Construídos e Transporte

$16^{\circ}$ USIHC - Congresso Internacional de Ergonomia e Usabilidade de Interfaces Humano Computador

CINAHPA | 2017 - Congresso Internacional de Ambientes Hipermídia para Aprendizagem.
CAMBIAGHI, Silvana Serafino. Desenho Universal: métodos e técnicas de ensino na graduação de arquitetos e urbanistas.

(Dissertação - Mestrado em Estruturas Ambientais Urbanas - FAUUSP). São Paulo, 2004.

COHEN, R.; DUARTE, C.; BRASILEIRO, A. Acessibilidade a Museus. Brasilia-DF:

MinC/Ibram, 2012.

DISCHINGER, M.; ELY, V. H. M. B.; PIARDI, S. M. D. G.: Promovendo acessibilidade espacial nos edifícios públicos. Florianópolis: MPSC, 2012.

DREYFUSS, H.. Design for People. N.Y. Simon and Schuster, 1955.

STEINFELD, Edward. Arquitetura Através do Desenho Universal. In: Anais do VI Seminário Ibero-Americano sobre Acessibilidade ao meio físico (VI SIAMF). Brasília: CORDE, 1994.

GOIS, Rodolfo. A metrópole e os mega-eventos. Implicações socioespaciais da copa do mundo de 2014 em fortaleza. Fortaleza, 2013. (UFC - Centro de Ciências departamento de Geografia - Mestrado em Geografia).

GOLDSMITH, Selwyn. Designing for the disabled. $3^{\mathrm{a}}$ ed. London: RIBA Publications, 1976.

IBGE: Instituto Brasileiro de Geografia e Estatística. Censo Demográfico 2010. Ministério do Planejamento, Orçamento e Gestão. Rio de Janeiro, 2011. Disponível em: http://www.ibge.gov.br/>. Acesso em: 09 fev. 2017.

PANERO, J; ZELNIK, M.: Las dimensiones humanas en los espacios interiores,

G. Gili, México, 1989.

PREISER, W. F.E.; OSTROFF E. Universal Design Handbook. NY:

McGraw-Hill, 2001.
ORNSTEIN, Sheila; ROMÉRO, Marcelo.

Avaliação Pós-Ocupação (APO) do ambiente construído. São Paulo: Studio Nobel: Editora da Universidade de São Paulo, 1992.

ORNSTEIN, S. W.; PRADO, A. R. de A.; LOPES, M. E. (Orgs). Desenho universal: caminhos da acessibilidade no Brasil. $1^{\text {a }}$ ed. são Paulo: Annablume, 2010.

SANTIAGO, Z. M. P.; LOPES, M. E.: Termo de Referência - Acessibilidade Física Pavilhão de Exposições. (impresso) Fortaleza, 2008.

SANTIAGO, Zilsa M. P. Acessibilidade no ambiente construído: o caso das escolas municipais de Fortaleza (1990-2003) Dissertação de Mestrado. FAUUSP, SP, 2005.

SANTIAGO, Zilsa M. P. Urbanismo Inclusivo como Meta no Novo Milênio. In: XXIX Congreso ALAS Chile - Crisis y Emergencias Sociales em America Latina. Santiago do Chile, 29 de setembro a 04 de outubro de 2013.

\section{Documentos}

Projeto Executivo de Arquitetura do Centro de Eventos do Ceará. Nasser Hissa Arquitetos Associados/ Architectus / Architechne. Fortaleza, 2010.

Consultoria /Projeto de Acessibilidade Centro de Eventos do Estado do Ceará. Zilsa M. P. Santiago e Maria Elisabete Lopes, 2008.

\section{Agradecimentos}

Agradecemos ao Escritório de Arquitetura e Urbanismo ARCHITECTUS que, gentilmente, nos cedeu os detalhamentos do Projeto do Centro de Eventos do Ceará. 